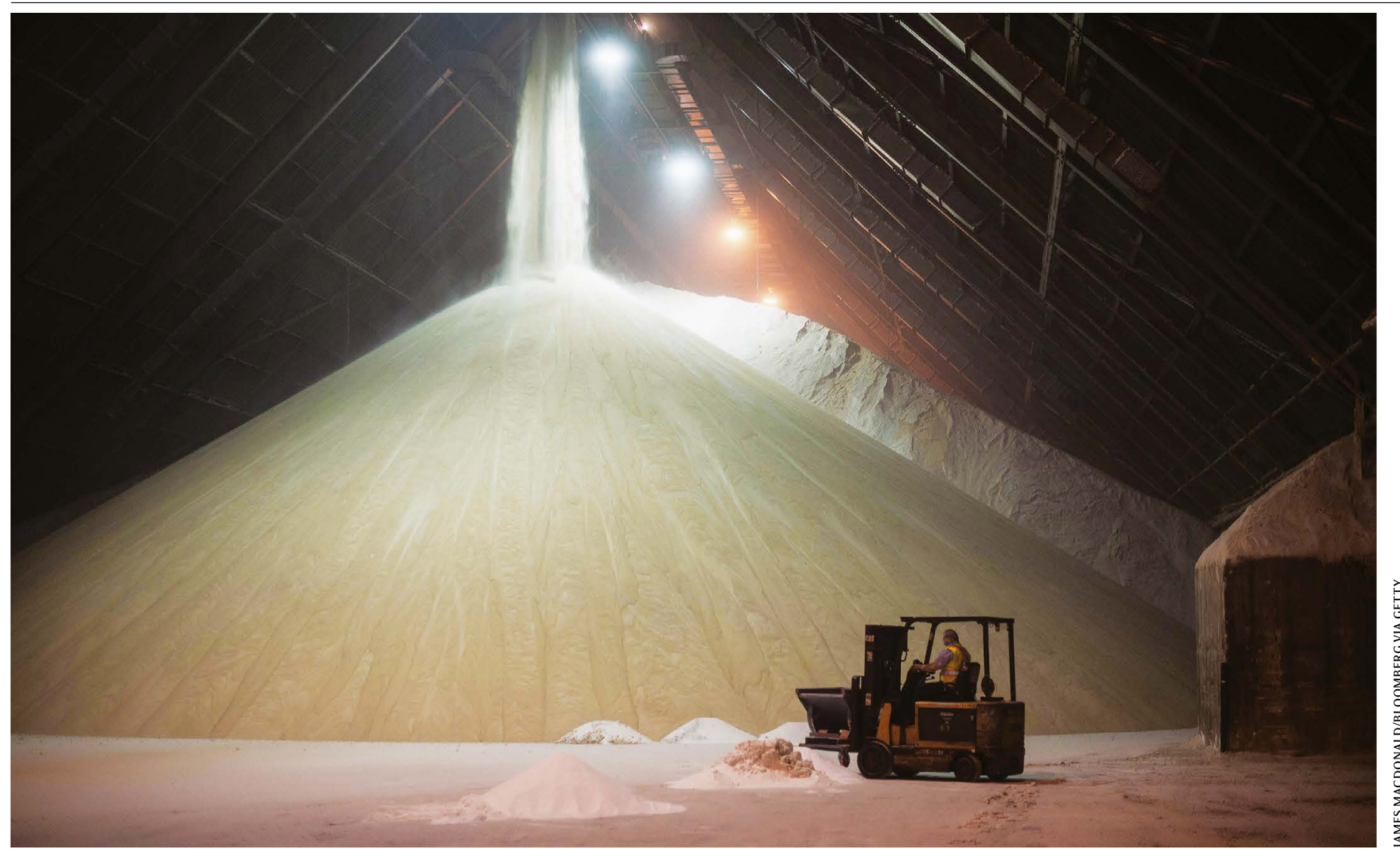

Sugar: multinationals have used the tobacco-industry playbook to stymie legislation aimed at cutting consumption.

\title{
Truth decay: when uncertainty is weaponized
}

\section{From tobacco to food and fuels, industries use denial, deceit and doubt to corrupt. By Felicity Lawrence}

n 2017, US presidential strategist Kellyanne Conway coined the phrase "alternative facts" to defend false claims about the size of the crowd at Donald Trump's inauguration. Numerous commentators lamented that we were entering a new era of Orwellian doublethink.

These are indeed upside-down times, as epidemiologist and former safety regulator David Michaels demonstrates in his excoriating account of the corporate denial industry, The Triumph of Doubt. Unwelcome news is automatically rebranded fake news. Inconvenient evidence from independent sources - say, about climate breakdown and fossil fuels, or air pollution and diesel emissions - is labelled junk science and countered with rigged studies claiming to be sound.

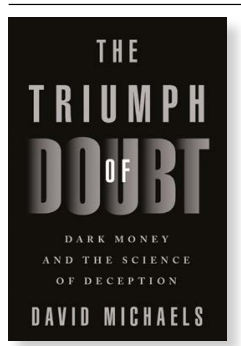

But it would be wrong to see truth decay solely as the preserve of today's populist politicians. Normalizing the production of alternative facts is a project long in the making. Consultancy firms that specialize in defending products from tobacco to industrial chemicals that harm the public and the environment have made a profession of undermining truth for decades. They hire mercenary scientists to fulfil a crucial role as accessories to their misrepresentations.

\section{Denial machine}

Michaels was among the first scientists to identify this denial machine, in his 2008 book Doubt is Their Product. His latest work combines an authoritative synthesis of research on the denial machine published since then with his own new insights gleaned from battles to control the toxic effects of a range of substances. He takes on per-and polyfluoroalkyls, widely used in non-stick coatings, textiles and firefighting foams; the harmful effects of alcohol and sugar; the disputed role of the ubiquitous glyphosate-based pesticides in cancer; and the deadly epidemic of addiction to prescribed opioid painkillers. In each 
case, Michaels records how the relevant industry has used a toolbox of methods to downplay the risks of its products, spreading disinformation here, hiding evidence of harm there, undermining authorities - all tactics from the tobacco industry's playbook.

The doubt in the title of both Michaels's books derives from a now-notorious memo written in 1969 by an unnamed executive at a subsidiary of British American Tobacco. It outlined a strategy for maintaining cigarette sales: "Doubt is our product since it is the best means of competing with the 'body of fact' that exists in the minds of the general public. It is also the means of establishing a controversy." By creating scientific disinformation about links between tobacco and disease, this malign strategy delayed regulation by decades and protected corporate profits.

Michaels's insider perspective on the doubt machine dates back to 1998, when he became chief safety officer for nuclear-weapons facilities at the US Department of Energy during the administration of US president Bill Clinton. Here, he had a ringside view of the tricks used by vested interests to dispute established science, intimidate the authorities and scupper regulation. In his first book, he described how the 'product defence industry' applied the tobacco template to asbestos, lead, plastics and toxic materials such as beryllium used in nuclear applications.

From 2009 to 2017, Michaels served as a senior regulator, appointed by president Barack Obama, in the Occupational Safety and Health Administration (OSHA). Here, he gathered even more material to show how deceptions have infected the body politic.

\section{Subverting the method}

The principles of scientific inquiry involve testing a hypothesis by exploring uncertainty around it until there is a sufficient weight of evidence to reach a reasonable conclusion. Proof can be much longer in coming, and consensus still longer. The product-defence industry subverts these principles, weaponizing the uncertainty inherent in the process. Its tricks include stressing dissent where little remains, cherry-picking data, reanalysing results to reach different conclusions and hiring people prepared to rig methodologies to produce funders' desired results.

Michaels acknowledges other doubt scholarship. This includes that of science historians Naomi Oreskes and Erik Conway in Merchants of Doubt (2010); nutritional scientist Marion Nestle's numerous books on the food industry, such as Soda Politics (2015)

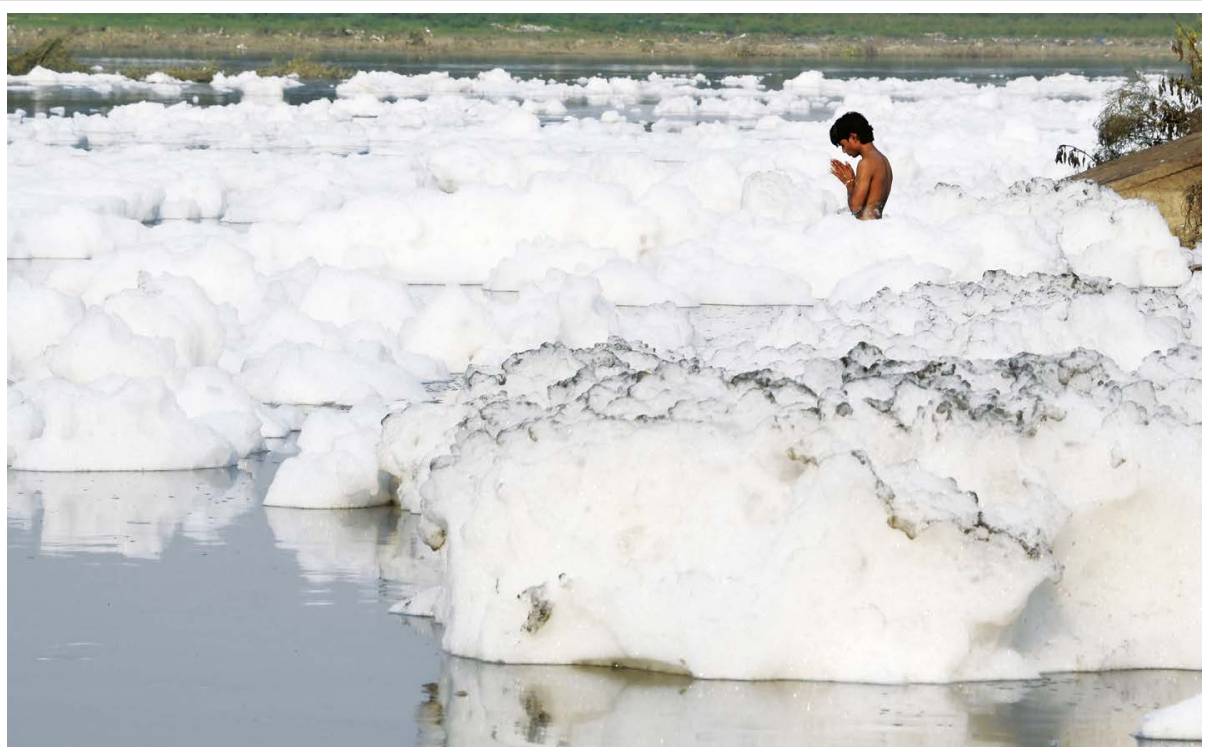

A man prays in foam caused by pollution in the Yamuna River in New Delhi.

and Unsavory Truth (2018); and journalist Jane Mayer's 2016 DarkMoney. That last book traced the funding that links climate-change denial to the libertarian right's ideological drive to shrink the state and deregulate industry.

Michaels names names fearlessly, pointing the finger at product-defence practitioners and the front groups and think tanks that masquerade as independent while taking

\section{"Creating scientific disinformation delayed regulation by decades and protected corporate profits."}

industry's shilling. Those wanting to check his allegations can find many previously unavailable source documents archived at the Triumph of Doubt Special Collection at https://toxicdocs.org.

\section{Emissions cheats}

So much of his material outrages, but two episodes stand out. One is the German car manufacturer Volkswagen's brazen malfeasance regarding its diesel engines. The company developed secret software so these engines could cheat emissions tests, allowing its vehicles to fraudulently pass stringent US checks on the disease-causing particulates in diesel exhaust. This was unintentionally uncovered in 2014 by students working on behalf of the campaign group the International Council on Clean Transportation in Washington DC, and confirmed the following year by the US Environmental Protection Agency. Michaels's account of the scientists prepared to launder their data to abet this criminal activity is forensic.

The second standout is his description of his years-long battle at the OSHA to reduce workers' exposure to silica particles from sand used in dozens of industries, from construction to steel manufacture and fracking. He and at least 50 staff members worked to collate evidence and counter a barrage of pseudoscientific objections and litigation.

Michaels, no longer required to be a non-partisan government official, reserves special criticism for the Republican Party. He argues that corporate polluters and manufacturers of dangerous products have long depended on the party to neuter public-health and regulatory agencies with phoney rhetoric about liberty and free-market enterprise. He wants stronger regulation, not because he does not care about freedom, he says, but because we cannot be free without the state's protection from harm.

The Triumph of Doubt is at times dense with technical detail, of necessity as Michaels prosecutes his case against companies known to be litigious. It is a brave and important book, raising the alarm about the systemic corruption of science.

Felicity Lawrence is special correspondent for The Guardian in London and author of Not on the Label and Eat Your Heart Out.

e-mail: felicity.lawrence@theguardian.com 